\title{
MARÍA ELENA GERTNER: CONVERSACIÓN EN TORNO A LA LITERATURA
}

\author{
Resha Cardone \\ Southern Connecticut State University \\ cardoner1@southernct.edu
}

María Elena Gertner (1927-2013) fue una pionera en la escena teatral y literaria chilena de los años 50 y 60. Comenzó su carrera artística a mediados de los años 40, al unirse al grupo de teatro experimental de la Universidad de Chile, ahora conocido como el ITUCH. Pronto se transformó en una de las actrices principales del grupo, y gracias a eso, pudo hacer varias giras en las Américas y en Europa (Trujillo 84). En 1953, viajó a Inglaterra, Francia y España donde conoció a algunos artistas europeos que contribuyeron a su desarrollo artístico (Lafourcade 163). Durante los inicios de su carrera dramática, formó parte del Teatro de Arte del Ministerio de Educación, del Teatro Ensayo de la Universidad de Católica y del Consejo de Teatro. Participó, además, en cine y televisión durante el gobierno de Salvador Allende. (Durante el régimen militar, todavía estuvo en proyectos de cine y televisión y es recordada por los cortes y censuras que tuvo su telenovela de 1984, La dama del balcón). Gertner fue directora, dramaturga y guionista de teleseries; más tarde, en los años 90, comenzó a dirigir talleres de teatro y de historia literaria en Isla Negra, donde pasó las últimas dos décadas de su vida.

En los años 50 y 60 se dedicó mayormente a la escritura, y en esas décadas publicó casi todos los géneros literarios: piezas dramáticas, un poemario ilustrado por Enrique Lihn, tres cuentos y siete novelas bestseller como Páramo salvaje (1963), La derrota (1965) y La mujer de sal (1967). Formó parte de la Generación de los 50, una promoción literaria auspiciada por la Empresa Editora Zig-Zag y nombrada por el crítico y autor chileno, Enrique Lafourcade, que incluyó a varias narradoras reconocidas, incluyendo a Margarita Aguirre, María Carolina Geel, Elisa Serrana y Mercedes Valdivieso. Entre los autores de su generación, Gertner se destaca por la diversidad de su quehacer artístico, su gran popularidad en los años 50 y 60, y dentro de su narrativa, por haber incluido temas tabúes -como la masturbación, la homosexualidad y la ninfomanía-que en aquél momento no se tocaban en la literatura chilena. 
Esta conversación, en la que participó la narradora chilena Pía Barros ${ }^{1}$, tuvo lugar el 10 de enero de 2004 en Isla Negra, Chile. El fallecimiento de Gertner en 2013 impulsó la publicación de este encuentro.

Resha Cardone (en adelante R.C.): ¿A qué edad y cómo empezó a escribir?

María Elena Gertner (en adelante M.E.G.): Empecé a escribir como a los nueve años. Fue una forma de comunicarme con mi abuelo materno porque él me escribía muchas cartas y yo le contestaba. Entonces, naturalmente empecé a escribir. Empecé a escribir jugando. Después comencé a dejar escritas las cosas que me impresionaban, lo que sentía.

R.C.: Después de su niñez, ¿cómo iba evolucionando su relación con la escritura?

M.E.G.: Luego escribí cuentos y, después de eso, pasé a la poesía.

Pía Barros (en adelante P.B.): ¿Alguna vez publicaste tus poemas?

M.E.G.: Publiqué un poema cuando tenía veinte años que se llamaba Homenaje al miedo ${ }^{2}$. Una señora de acá, de Isla Negra, llamó una vez al museo [la Casa Museo Isla Negra, de la Fundación Pablo Neruda] y dijo que tenía un ejemplar del poemario y que me lo vendía. Y le iba a decir que me interesaba, pero no ha vuelto a aparecer la señora. El libro está agotado.

P.B.: ¿No tienes copia de eso?

M.E.G.: No tengo.

R.C.: Y después de publicar ese poemario, publicó algunos cuentos, ¿no?

M.E.G.: Publiqué varios cuentos. Me gusta mucho ese género y la narrativa en general. La novela también, pero lamentablemente corté la escritura de novelas. Ahora estoy intentando hacerlo de nuevo después de muchos años de silencio. (Que fue obligado en realidad.)

R.C.: ¿Por qué fue un silencio obligado?

M.E.G.: Porque pasó lo siguiente: cuando me separé de Pepe, mi marido, ya no tenía cuarto propio, ya no tenía esa tranquilidad para poder escribir.

Pía Barros (n. 1956) ha tenido una carrera artística múltiple que incluye sus propias publicaciones narrativas, la dirección de talleres literarios y la realización de varios proyectos de activismo editorial. Desde 1985, ha publicado dos novelas y ocho colecciones de cuentos, la más reciente, El lugar del otro, fue reconocida con el Premio Altazor a la mejor narrativa publicada en el año 2011.

2 Este poemario fue publicado en 1950 por los Talleres de la Imprenta Amistad como edición limitada y numerada. El libro incluye un poema largo y varias ilustraciones del poeta, dramaturgo y novelista chileno, Enrique Lihn. 
P.B.: ¿En qué año fue eso?

M.E.G.: Fue el año 1967 o 1968. Entonces yo tenía que pensar en que tenía una hija que mantener. Además, yo era totalmente de izquierda, del partido de Allende, y mi marido no lo era. Él se casó de nuevo, y pronto se fue de Chile a Europa por la situación política de aquel tiempo. Entonces, tuve que empezar a pensar en ganarme la vida de alguna manera. Hasta allí mis derechos de autor habían sido muy importantes para mí porque me dejaban comprar mis cosas, pero no daban para mantener a una bebé y además una casa. Yo tenía todo en mis manos, y por lo tanto, no tenía la tranquilidad para escribir. Por eso te hablo del cuarto propio que Virginia Woolf define como las necesidades mínimas que una mujer necesita para poder dedicarse a escribir. Este espacio no lo tenía. Al contrario, tenía otras necesidades que eran: ¿qué se va a comer en esta casa? ¿cómo se va a pagar la luz? ¿cómo se va a hacer esto y lo otro? Entonces en ese instante volví a lo que era mi oficio anterior -el teatro. Y todo eso me quitó absolutamente el tiempo, o sea, la tranquilidad y el tiempo para poder desarrollar novelas y cuentos.

R.C.: Usted actuaba en la televisión, ¿no es cierto?

M.E.G.: Claro, actuaba. Empecé de nuevo porque yo había dejado de lado lo de actuar. Entonces empecé de nuevo a actuar porque eso era un oficio más simple, más fácil para mí. Volví al teatro y a meterme en la televisión y todo eso me acaparó. Esto sucedió después del golpe militar cuando me quedé sin trabajo. Yo trabajaba para el Canal 7 durante el gobierno de Allende y de allí, después del golpe militar, quedé sin trabajo. Después tuve que empezar a meterme de nuevo en el teatro. Durante el régimen no había condiciones para poder seguir escribiendo normalmente, para seguir escribiendo todo el tiempo, con frecuencia, con disciplina.

R.C.: ¿Y volvió a escribir después?

M.E.G.: No, realmente no volví a escribir como antes. Después me dediqué a escribir libretos para la televisión. Después volví a entrar de nuevo al Canal 7, pero allí había presiones tremendas porque durante el gobierno militar estar en el 7 era estar sometida a una constante censura.

P.B.: El 7 tenía vigilancia interna, además.

M.E.G.: Sí, era terrible. Había que rehacer y cortar todo. Era horrible.

R.C.: ¿Era un canal izquierdista?

P.B.: Originalmente el Canal 7 fue del gobierno [de la Unidad Popular], pero después fue de Pinochet. No había canales alternativos a causa de los bandos militares y los modos de censura. El modo de redactar las noticias tenía un parámetro, supuestamente un corte editorial, pero en realidad había una serie de palabras que no se podía decir y temas que no se podían tocar. Todo eso llegó también a las teleseries. Todos los temas eran tabúes.

M.E.G.: Incluso parte de la primera teleserie que yo hice—La dama del balcón (1984)—la charquearon, la cortaron entera. Todo el elenco era de izquierda. Parte de la obra sucedía durante la Segunda Guerra Mundial, y entre los personajes había un padre y su hijo nazi. 
El gobierno militar censuró la obra porque el uniforme nazi era igual al de los milicos chilenos. Y efectivamente el uniforme era igual porque fue copia del de allá. Por eso la censuraron entera, la cortaron, la hicieron desaparecer. La censura pasó así. En otro momento hice una teleserie corta que ocurría donde un anticuario. Decidí que necesitaba una extra que iba a comprar un cuadro. Necesitaba a una persona que pudiera hablar, no una actriz realmente, sino una extra que pudiera decir dos o tres palabras. Esta escena se grabó y la censura la cortó porque la voz de la mujer que pusieron fue igual a la de la señora Lucía Hiriart de Pinochet.

P.B.: Además, la autocensura era mucho más violenta que la censura misma. La gente se puso tan histérica que su nivel de censura era infinitamente mayor de lo que ejercía directamente Pinocho.

M.E.G.: Siempre trabajábamos diciendo "esto lo van a cortar, este otro, no". Era espantoso.

R.C.: Y antes de eso, cuando usted se dedicaba a la narrativa, ¿tenía conciencia de pertenecer a una generación literaria?

M.E.G.: Debes estar hablando de la Generación del 50. Bueno, estaba dentro de ella pero yo no considero que la Generación del 50 fuera un movimiento generacional. Más bien fue una cosa que inventó Enrique Lafourcade. Realmente no era un movimiento generacional: eran escritores de pensamientos totalmente opuestos. Nada nos marcaba como una generación, pero yo pertenecía a ella.

R.C.: ¿Y usted se reunía con otros escritores de la época? ¿Había, por ejemplo, una comunidad de escritores o escritoras?

M.E.G.: Había gente que era muy amiga mía. Mercedes Valdivieso fue una gran amiga porque éramos amigas no más, porque pensábamos igual, porque estábamos en el mismo bando las dos. Después [la Empresa Editora] Zig-Zag organizó muchas giras de escritores, y en estas giras viajábamos por todo Chile. Pero tu pregunta es sobre los grandes amigos. Tenía grandes amigos, pero no eran gente de la Generación de los 50 . El amigo que yo realmente adoraba era Manuel Rojas [Sepúlveda] pero él era mayor que yo. No era de mi generación. Manuel y yo fuimos amigos también fuera de Chile, en Buenos Aires, porque era mi amigo de antes. Pero lo que tú me preguntas, que si la gente de la Generación de los 50 nos juntábamos o hacíamos un grupo, la respuesta es no. Fui amiga de José Donoso pero no porque él estuviera en la Generación de los 50 y yo también, sino porque éramos amigos, no más.

R.C.: ¿No había conciencia de grupo?

M.E.G.: No, para mí, no.

P.B.: ¿Y conciencia de ser un grupo de mujeres?

M.E.G.: ¿Conciencia de qué? ¿De pertenecer a un grupo de mujeres escritoras?

P.B.: Lo que pasa es que en los años 50 es la primera vez en la historia de Chile cuando hay una gran proporción de mujeres escritoras. Hay un gran grupo de mujeres escritoras 
produciendo: Margarita Aguirre, Elisa Serrana, María Carolina Geel, Mercedes Valdivieso. No son dos o tres, sino muchas.

M.E.G.: No tenía mucha conciencia de eso en aquel momento.

P.B.: La conciencia grupal acontece de los 80 en adelante, parece.

M.E.G.: No recuerdo yo.

R.C.: Y a pesar de no tener conciencia de formar parte de un grupo de mujeres escritoras ¿se apoyaba en alguien, en algún maestro o maestra?

M.E.G.: Cada una tiene sus influencias, pero realmente no tenía maestros directos.

R.C.: ¿Y cuáles eran esas influencias?

M.E.G.: Yo admiraba a Fyodor Dostoyevsky. La Virgina Woolf escribió cosas fuertes e increíbles y por supuesto la Simone de Beauvoir fue una gran influencia.

P.B.: Yo leía tus libros a escondidas. Leía tus libros que estaban prohibidos en mi casa porque eran eróticos y cochinos y yo los encontraba espectaculares. Yo siempre he tenido muy claro que mi influencia eres tú.

M.E.G.: ¡Pero qué cosa más linda! Creo que mi gran influencia era Dostoyevsky.

P.B.: ¿Las mujeres se reunían en algún momento? ¿Tú mostrabas a la Mercedes Valdivieso tus textos? ¿O alguna vez ella te los mostraba a ti? ¿Discutían los textos? ¿O los discutían directamente con la editorial?

M.E.G.: Directamente con la editorial. No había una conexión grupal. Con la Mechi [Mercedes Valdivieso] discutía la política, pero no nuestros textos. Con la Elisa Serrana, por ejemplo, no recuerdo que hayamos tenido ningún punto de contacto.

R.C.: ¿Usted sabe si las otras mujeres de la Generación de los 50 se reunían?

M.E.G.: No sé. Margarita Aguirre vivía en Argentina. Venía acá para ver a Pablo Neruda. Yo la veía a veces acá y en Argentina porque yo también viví en Argentina. Pero aparte de la Mechi no tenía otras amigas escritoras.

P.B.: ¿Qué otra dramaturga había?

M.E.G.: Había viejas dramaturgas: la María Asunción Requena era importantísima.

P.B.: ¿No había otra dramaturga de la época?

M.E.G.: ¿Pero tú me consideras dramaturga a mí? Yo no creo. Yo hice algunas cosas en el teatro, pero no era realmente dramaturga. He hecho mucho más ahora. Escribí algunas obritas de teatro, pero no las clasifico como buenas obras, y no continué escribiendo teatro.

P.B.: Si yo hablo con otra gente que te conoció y que trabajó contigo en algún minuto se refieren a ti como dramaturga o como actriz. Y me da risa porque yo me refiero a ti como escritora. Eso es lo interesante de ti: la multiplicidad. Tú fuiste dramaturga en un momento en que no había dramaturgas de tu generación. Las dramaturgas que había eran 
bastante mayores, como la Isidora Aguirre y la María Asunción Requena. Escribías en un instante de muchas rupturas y tú hiciste muchas rupturas: rupturas temáticas y formales en el teatro y en las teleseries que pueden parecer ahora una tontera pero era una ruptura contra todo lo que te digo. Tú tienes más importancia de lo que crees.

M.E.G.: A esto no le di mayor importancia. Yo he escrito tres o cuatro obras de teatro, algunos libretos de televisión y guiones para el cine. Y cuando era muy joven, vino Pierre Chenal $^{3}$ a Chile y me pidió que escribiera el guión [de la película] Confesión al amanecer (1954). Entonces no le daba importancia.

P.B.: Pero la tienes. Hay que reconocer que la tienes.

M.E.G.: Bueno, vamos a volver atrás. A los nueve años comencé a escribir cosas de niña chica. Había una revista que se llamaba Margarita, y a los trece años, mandé unos cuentos y cositas chicas a esa revista y me los aceptaron. Cuando salí del colegio, yo pretendía estudiar psicología. Pero [el actor] Eduardo Naveda tuvo mucha influencia en el teatro que se estaba haciendo en Chile, y él me dijo que tenía talento para ser actriz. Aparte de esto, yo había conocido a un señor que me persiguió en la calle y me ofreció una prueba como de Hollywood, y me preguntó si a mí me interesaba actuar. Yo tenía como 17 años. Me hicieron unas pruebas y actué en un papelito mínimo en una película muy mala que se llamaba Casamiento por fuera (19[50]). Yo la encontré horrible, pero bueno. De aquí para adelante, me di cuenta de que podía actuar e ingresé en la Escuela de Teatro de la Universidad de Chile, que fue muy buena y me dieron papeles inmediatamente. Es por eso que hay mucha más gente que me conoce más como actriz que como escritora. Ahora, escribir profesionalmente lo vine a hacer después.

R.C.: ¿Usted quería ser artista en su niñez?

M.E.G.: No. Siempre me cargaban los niños "centro de mesa" y me cargan hasta hoy. Tuve conciencia de que era actriz y que tenía talento. Sabía que podía escribir, y me gustaba más escribir. Ahora soy profesora de teatro pero me he dado cuenta de que hay algo que no se enseña: el talento.

R.C.: Y cuando usted comenzó a escribir prosa, ¿hubo un evento clave que la impulsó a hacerlo?

M.E.G.: No uno. Hubo muchos, posiblemente. Es decir, una siempre escribe motivada por muchas cosas. Una no comienza en frío y se pone a planear que va a escribir una novela sobre determinada cosa. No pasa así.

3 Pierre Chenal (1904-1990) era un cineasta y guionista francés que ganó cierta fama en los años 30 por sus películas de cine detectivesco. Por ser judío, tuvo que huir de Francia a Argentina en 1942. Viajó a Chile donde pidió que Gertner escribiera el guión de Confesión al amanecer, una película que después él dirigió. 
P.B.: ¿Qué llegó primero, los premios o las publicaciones? Hubo premios antes de la publicación del primer libro, ¿no?

M.E.G.: La publicación fue primero. Ese concurso, el CRAV 4 , que gané con [mi cuento] "El invencible sueño del coronel"...

P.B.: El CRAV y la antología que Lafourcade editó ${ }^{5}$ donde se publicó [tu cuento], "Niñita".

M.E.G.: Y hay otro cuento que publicó la Editorial Álvarez en Argentina, "Por la ruta que señala el viento". Un buen cuento, pero no lo tengo. Lo que escribí son tres o cuatro cuentos, nada más.

R.C.: Son pocos los cuentos pero todos son sumamente rupturistas y feministas. ¿Qué opina usted sobre el feminismo?

M.E.G.: Creo que el feminismo era una necesidad urgente. Es una necesidad urgente. A nivel mundial, creo que es algo muy importante, pero en Chile funciona mal. Tal vez fui feminista antes de tiempo. Toqué temas que la gente no tocaba. Actué de una forma que la gente no actuaba. Hice muchas cosas que la gente no hacía. Entonces, ¿era yo feminista? Tal vez. No me di cuenta. Tal vez lo era, pero no había ningún movimiento feminista organizado en Chile. No conozco los movimientos feministas chilenos. Yo considero a la Pía una escritora feminista por sus temas y su militancia.

R.C.: ¿Usted intentó cultivar alguna temática feminista en su obra de ficción?

M.E.G.: Deliberadamente, no. Salió solo.

R.C.: ¿Y en el teatro?

M.E.G.: ¿Entre las cosas que yo escribí? No sé. No tengo mucha conciencia.

R.C.: ¿Cuál era la reacción del público ante sus textos?

M.E.G.: La reacción era excelente. Tuve siempre novelas de dos, tres, cuatro ediciones, y aunque dijeran que eran malas, se vendían todas.

R.C.: ¿En algún momento usted se sintió criticada por su comportamiento público y temas literarios no tradicionales?

M.E.G.: Me linchaban, mi amor. ¿Cómo no iba a sentirme criticada? Tendría que haber sido sordomuda para no sentirme criticada. Hablaban pestes de mí. Todavía hablan

$4 \quad$ En 1963 "El invencible sueño del coronel” fue publicado en una antología por haber ganado el primer lugar en un concurso literario patrocinado por la Compañía Refinería de Azúcar de Viña del Mar (CRAV).

$5 \quad$ Se refiere a la Antología del cuento nuevo chileno (1954), la colección de ficción breve en la que su editor, el autor y crítico, Enrique Lafourcade, nombró y definió la Generación de los 50 en el prólogo y estableció los miembros del grupo en la selección de escritores seleccionados. 
pestes de mí. Pero no importa. Eso es una cosa que tú aprendes que no importa. Tú lo pasas por alto. Pero, claro, me criticaban y después salió otra edición de un libro mío. Mis libros vendían. Y era importante también que fuera una buena actriz. Eso siempre era lo que más importaba.

R.C.: ¿Conoce usted la obra de las escritoras chilenas actuales, aparte de la de Pía?

M.E.G.: Conozco a algunas. Aparte de la Pía, no hay otras escritoras que me encanten, pero no he leído a todas. En esta isla donde vivimos [en Isla Negra] estamos bastante aislados: no hay eventos culturales salvo los que se hacen aquí en el museo [de la Fundación Pablo Neruda], y en la librería del museo solamente se venden los libros de Neruda. Entonces no estoy absolutamente informada. De la Pía creo que he leído casi todo. El libro que realmente me impactó fue $A$ horcajadas (1990) que tiene algunos cuentos alucinantes.

R.C.: ¿Usted sabía algo del estallido de mujeres escritoras chilenas en los años 80 y de los talleres literarios clandestinos que Pía dirigió durante la dictadura?

M.E.G.: Sí, estaba al tanto.

P.B.: Hay que entender que enseñé mucho tus textos en mis talleres. Todo el mundo sabe que, en términos de la Generación del 50 en Chile, lo que más se difunde era la Margarita Aguirre y la Elisa Serrana, y después en los ochenta, a la Mercedes Valdivieso, que en su época tampoco fue tan difundida. Lo que ellas veían como registro, por ejemplo en los diarios, eran entrevistas mucho más sociales porque los textos de la María Elena eran mucho más radicales y mucho más interesantes en términos de prosa y en términos de mirada. Entonces, empezamos a perseguirte con la [periodista] Margarita Cea, que era mucho más fanática y también amiga mía en el colegio. Buscábamos dónde estabas porque queríamos hacerte un homenaje.

M.E.G.: En todo ese tiempo que me vine a vivir acá en Isla Negra, perdí el contacto. Yo te vi a ti, Pía, pero a otras no.

R.C.: Es obvio que ustedes dos se admiran mucho. ¿Creen ustedes que hay una conexión textual entre sus obras o entre sus figuras públicas artísticas rebeldes?

M.E.G.: No hay una buena respuesta a esto. Hay una conexión porque a mí me hubiera gustado escribir algunas de las cosas que escribió la Pía.

P.B.: Bueno, en mi caso, tú ya sabes que te admiro por lo que has hecho. Pero aparte de eso, en tus cuentos, como en "El invencible sueño del coronel", hay una cantidad de elementos de transgresión escritural que tienen que ver con los modos de narrar que me interesan: que de repente te hable del sueño, de repente la otra conciencia, de otros niveles de conciencia, de la protagonista que uno no sabe si lo que está pasando sucede en el presente o en el pasado. Son cosas muy interesantes. Y nos muestras modos de amar súper desgarrados, como en [tu novela] La derrota (1964). A mí me marcó tu estética por siempre. Es súper importante haberte leído y reconocer, además, tu influencia en mi trabajo literario. No lo reconocí hasta años después cuando alguien me preguntó en una entrevista quiénes eran mis influencias, y yo hablaba de Margarite Duras, que por 
supuesto era mi delirio de escritora. Y después me preguntó qué escritora chilena me influyó, y le dije que la única que yo seguí fervientemente era la María Elena Gertner. Leí a las otras, pero la única que seguí fue a la Gertner. Y en este momento me di cuenta de que tú eras la marca crucial que dividía un modo de escribir, hasta cuando yo quise tener una estética propia. Yo no podía tener la propia sin reconocer de dónde venían mis cuentos, y mis cuentos vienen de allí, de María Elena.

M.E.G.: Me dejas totalmente fascinada. No tenía idea.

R.C.: Pía, ¿a usted le interesaba María Elena como figura pública?

P.B.: Ella siempre me interesó. Era desafiante. Pero en cosas puntuales. ¿Tú tienes cero noción de la importancia que tienes en la literatura, María Elena?

M.E.G.: Cero.

R.C.: Por ende, el ego tuyo va absolutamente por el teatro.

M.E.G.: No, no diría eso. Si me dicen que Cuarto Propio quiere reeditar La mujer de sal (1964) me infla, me llena de felicidad. Y si me editaran las demás cosas, también.

P.B.: ¿Tú tienes conciencia de los temas que tú tocaste y de la importancia que tienen literariamente? En La derrota, por ejemplo, presentas la clase alta empobrecida que siempre fue tocada con mucho cuidado; que siempre tiene justificaciones. En esa novela, tú tomas a la mujer y la haces charqui, la muestras no en la precariedad sino en su debilidad, y por ende, eres tal vez una de las primeras - posteriormente lo hace Isabel Allende en $\mathrm{La}$ casa de los espíritus (1982) — que desde la clase alta tomas la fenomenología de clase y destruyes toda la estructura social que se ha armado para justificar esta fenomenología. Eres la primera escritora que menciona la homosexualidad en un texto. Eres la primera que usa la pulsión del deseo. En [tus novelas] Páramo salvaje (1963) y La mujer de sal (1967), están las mujeres deseantes. Tú eres la primera que lo hace. Antes no hubo otra. Y lo haces desde el cuerpo, no solamente desde la cabeza. Son cuerpos que desean, y no siempre racionalmente. Acá el deseo es irracional, y no está siendo justificadosimplemente se está mostrando. Y eso es un cambio radical en la literatura de mujeres. Así como la [María Luisa] Bombal puso esa necesidad de tener un amante, de otro que cumpla la función del deseo como base de un texto, tú fuiste la primera en hacerlo, y por ende, provocas un cambio radical en las miradas de otras literaturas que vinieron después. Provocaste un cambio crucial en la literatura.

M.E.G.: Bueno, yo tengo plena conciencia de todo esto que tú me estás hablando, pero no de haber tenido esta importancia. Todo lo que me has enumerado lo reconozco; o sea, de mostrar a una mujer de clase alta por dentro, de mostrar que lo más terrible de lo que podía haber mostrado es eso de haberse enamorado y de tener esa calentura loca con este tipo, de no prestar nada de atención a las expectativas sociales, de enamorarse de un hombre que no tenía nada que ver con lo que se le enseñó que debía ser; que tenía olores y voluntad, todo lo que no tienen los hombres de su clase. Y eso de terminar como una dueña de pensión muy de tercer orden. Ese personaje es uno muy querido. Intenté tratarla con amor. 
P.B.: No es tanto amar a este personaje sino involucrarse con él. El amor te hace mentir, y en este caso, eres muy honesta acerca de la protagonista. Ella se justifica a sí misma pero la narradora no la justifica. La narradora no está justificando, está mostrando. No la tratas bien.

M.E.G.: No es una mujer como yo. La protagonista de La mujer de sal es mucho más parecida a mí.

R.C.: Me parece que hay semejanzas entre las dos, no solo en sus textos, sino que también en las figuras públicas que han creado. Las dos han sido mujeres rebeldes, las dos han hecho cosas que supuestamente no se debían hacer en el espacio público, ya sea por las normas sociales que rigen el comportamiento de la mujer o por su forma de desafiar los bandos militares durante la dictadura.

M.E.G.: A nivel público, claro, creo que hicimos cosas que sí se debería hacer. Eran propias de los tiempos. No había otro modo. Me arrepiento de no haber hecho más cosas.

R.C.: ¿Usted tenía conciencia de ser una maestra de las escritoras que vinieron después?

M.E.G.: Jamás.

R.C.: ¿Y qué le parece haberlo descubierto ahora?

M.E.G.: Me ha dejado muy fascinada. Me hace muy feliz.

R.C.: ¿Cómo es su vida actual? ¿Hace alguna actividad literaria en este momento?

M.E.G.: Mi vida actual está totalmente dedicada a mis talleres. Yo me vine a vivir en este pueblo porque mi hija se casó y se separó. Entonces mi madre estaba viviendo aquí y tenía esta casita. [La izquierda] necesitaba gente para trabajar. Lucho [el psiquiatra, Luis Weinstein] formó la voz cultural comunitaria de la Isla Negra de izquierda. Y en este lugar cultural comunitario, él llamó a formar talleres a Ricardo Mesa, el escultor, y a Luis Advis con su conjunto musical. Y Lucho [Weinstein] me preguntó si yo podía hacer talleres de teatro. Entonces empecé a formar talleres de teatro y de Historia de la Literatura, en este pueblo donde la mayoría de las personas nunca había visto una obra de teatro y no conocía, en su gran mayoría, más que "la comedia" y la teleserie, pero el teatro no lo había visto. Entonces formé estos talleres y empezaron a funcionar primero en una casita, pero después, a raíz de esto, me llamó la municipalidad a hacer la parte cultural del equipo. Duré muy poco ya que, por supuesto, el alcalde era absolutamente inculto y fascista. Hice un catastro sobre el nivel cultural de la gente de Isla Negra. En este catastro en que participaron todas las escuelas, todos los colegios y los apoderados me di cuenta de que el nivel cultural era mucho menos de lo peor de lo que tú te podías imaginar. Los de cuarto medio decían que Gabriela Mistral era una cantautora. Los únicos nenes que contestaban en forma más o menos normal, fueron los de la escuela de aquí de Isla Negra, porque aquí está la casa de Neruda. Entonces puse mucho hincapié en la Historia del Teatro porque a través de ella empieza a salir la historia real. Empecé a formar actores, empecé a mostrar obras y poco a poco comencé a crear el Grupo Alta 
Marea de Isla Negra. ${ }^{6}$ Y este grupo y los talleres me han dado muchos dolores de cabeza y mucha satisfacción porque he visto que en los trece años que he vivido en este pueblo y en doce años de actividad, he cultivado un interés por actuar. He despertado algo.

P.B.: ¿Quién te paga los talleres?

M.E.G.: Me paga el museo [de la casa de Neruda]. Me pagan muy mal porque no solamente hago clases de actuación y de Historia del Teatro sino que también dirijo y adapto las obras. Me gusta hacerlo, y esto es lo que me compensa. Algunas personas me han preguntado por qué no hacía un taller literario. Y cuando me di cuenta de la capacidad de la gente, del estado mental de la gente, de su currículum, me di cuenta de que era totalmente imposible. La gente lee poco o nada, entonces era muy difícil hacer un taller literario. Tampoco quería hacer un taller literario para los veraneantes. Quise hacer algo por este pueblo y por eso me he dedicado a dar talleres de actuación.

\section{BIBLIOGRAFÍA}

Lafourcade, Enrique, ed. Antología del nuevo cuento chileno. Santiago: Empresa Editora Zig-Zag, S.A., 1954. Impreso.

Trujillo, Virginia Delam. The Female Problematic as Reflected in Novels of Three Chilean Women Writers of the Generation of 1950. Diss. University of California, Irvine, 1983. Impreso.

6 Gertner dirigió talleres en Isla Negra desde 1992 hasta su muerte en 2013. Su taller Alta Marea nació a finales de 1992 a raíz del éxito del proyecto de fin de año del primer taller, la representación de una obra escrita y dirigida por Gertner titulada "Las visitas". Ana Roa Soto, una alumna de la escritora, sigue dirigiendo el taller Alta Marea hasta el día de hoy. 